\title{
COVID-19 pandemic and assessments of final year medical students in psychiatry: an innovative Sri Lankan experience
}

\author{
A Hapangama, K A L A Kuruppuarachchi
}

\section{Introduction}

We would like to share our experience in conducting online examinations for final year medical students in psychiatry at the Faculty of Medicine, University of Kelaniya, Sri Lanka with the readership of the Sri Lanka Journal of Psychiatry.

Since 2018, final year assessments in psychiatry in all state medical schools in Sri Lanka consist of a multiplechoice question paper, a structured essay question paper, a "traditional" long case, a viva voce examination, and a modified objective clinical assessment (MOCE). In most of these medical faculties, the viva voce and the MOCE are held every two months soon-after a group of 32-36 students complete their eight- week psychiatry clerkship. Both the viva voce examination and the MOCE have been developed as face-to-face assessments with two examiners marking each student. The MOCE also involves two examiners, where the latter observe a student's interaction with a simulated patient or a caregiver during a given time limit.

The Ottawa consensus statement for good medical assessment identifies construct validity, reproducibility, equivalence, acceptability, feasibility, educational benefit, and timely feedback as key elements for successful medical assessment (1). The validity and efficacy of online assessment in clinical reasoning and information gathering have been previously reported (2). There is also some evidence regarding the use of 'tele OSCEs' for assessment of clinical skills (3). It has been shown that virtual patient encounters are valid to extrapolate and induce the same emotional responses as in real standardized encounters, in assessment of communication skills, and that this form of communication has no difference in patient-perceived information exchange, interpersonal relationship building, and shared decisionmaking compared with the face-to-face communication $(4,5)$.

During the height of the second and third wave of the COVID-19 pandemic in Sri Lanka, any form of face-face interaction among a group of people was discouraged. Considering that the two examiners and the simulated patient/caregiver would have to sit in a closed environment for more than three hours on a given day, we had to think of "out of the box methods" to assess our students, that ensured the physical safety of the students, simulated patients/caregivers, and the examiners.

We planned conducting both the above forms of assessments (viva voce and MOCE) on an online format to minimize any face-to-face interactions. We ensured uniform internet connectivity for all the stakeholders by providing rooms for all parties in the same premises (except for the external examiner). Examination conditions were maintained by ensuring that the questions were made available only once the student arrived in the room allocated to them, which had a laptop with the examination link installed in it. This minimized the sharing of username and password with the students and the need for the use of personal electronic devices. The identity of the students was confirmed by the examiners.

Most importantly, discussions were held with students well before the assessments, to ensure physically safe ways of conducting the examinations while adhering to health guidelines. The students preferred to have the assessments conducted via an online format, rather than to have the examinations being postponed. After the assessments concluded, we received formal student feedback, and most students reported that they did not see any difference between face to face and online format of the examinations. A minority were concerned about the stability of the connectivity and whether the examiners could hear them clearly.

Overall, we believe that we (the academics and the students) had a positive outcome in conducting the above examination during 2020 and 2021 . We recommend the adoption of virtual examination techniques for assessment of undergraduate medical students during their examinations, especially during times such as these. However, we also acknowledge that these methods will need formal validation in our setting.

\section{Acknowledgements}

We wish to thank the administration of the University of Kelaniya (Vice Chancellor, University of Kelaniya and the Dean Faculty of Medicine and the Senate), who 
gave us approval to conduct the examinations in this manner, given the health situation of the country, and the Department of Medical Education, the Computer Centre and other academic and non-academic staff of the Faculty of Medicine for logistical support, and the students who wanted to sit the examination in this novel manner.

\section{Conflicts of interest}

None declared.

A Hapangama, K A L A Kuruppuarachchi, Department of Psychiatry, Faculty of Medicine, University of Kelaniya, Sri Lanka

Corresponding author: A Hapangama

Email: ahapangama@kln.ac.lk

iD http://orcid.org/0000-0002-5477-5050

\section{References}

1. Norcini J, Anderson B, Bollela V, et al. Criteria for good assessment: consensus statement and recommendations from the Ottawa 2010 conference. Med Teach. 2011; 33(3): 206-14.

2. Mooney CJ, Peyre SE, Clark NS, Nofziger AC. Rapid transition to online assessment: practical steps and unanticipated advantages. Med Educ. 2020; 54(9): 857-58.

3. Lara S, Foster CW, Hawks M, Montgomery M. Remote assessment of clinical skills during COVID-19: a virtual, High-Stakes, Summative paediatric objective structured clinical examination. Acad Pediatr. 2020; 20(6): 760-61.

4. O'Rourke SR, Branford KR, Brooks TL, et al. The emotional and behavioural impact of delivering bad news to virtual versus real standardized patients: a pilot study. Teach Learn Med. 2020; 32(2): 139-49.

5. Guiton G, Hodgson CS, Delandshere G, Wilkerson L. Communication skills in standardized-patient assessment of final-year medical students: a psychometric study. Adv Health Sci Educ Theory Pract. 2004; 9(3): 179-87. 